\title{
Arbor
}

\section{La «agnosia» del creyente}

\section{José Gómez Caffarena}

Arbor CLXXI, 676 (Abril), 833-839 pp.

Agnosia, un término griego para ignorancia, fue usado por un cristiano del siglo $V$ que tuvo gran influjo para caracterizar el modestísimo conocimiento (gnosis) de Dios a que pueden aspirar los humanos. El creyente reflexivo actual recoge con sumo interés esa modestia y encuentra en ella la clave de una real cercanía con aquellos agnósticos actuales que siguen valorando la teología. Coinciden ambos en lo que saben (sobre el mundo y el hombre) y en el interés por las cuestiones-límite; ante las que tienen convicciones (y actitudes) diferentes.

Cuando mi buen amigo Xavier Quinzá, coordinador del presente monográfico sobre «el enigma de la religión», me pidió amablemente una breve aportación, encontré oportuno, tomando del modo más literal el título, pensar lo que para el creyente tiene de enigma la religión. El tema se me concretó al leer la colaboración de ese otro buen amigo, Ignacio Sotelo, en la que reivindica para el agnóstico una auténtica preocupación por la teología.

Habiendo compartido año tras año con Sotelo esa aventura de diálogo en profundidad que hemos llamado «Foro sobre el Hecho Religioso", he sido testigo de que lo que dice en su escrito sobre el acercamiento del agnóstico a lo religioso y lo teológico no es una idea adventicia; y que, en él, desde luego, no ha sido ninguna veleidad. Sus ideas son así para mí una invitación a intentar expresar lo que entiendo ha sido motivo de fondo a la vez que resultado de ese esfuerzo de diálogo intelectual sobre lo religioso al que he dedicado una buena parte de mi vida.

Buscando ante todo expresarlo concentradamente en un título, no he encontrado, ni creo podría encontrar, otro mejor que el que he puesto: $l a$ «agnosia» del creyente. 


\section{¿Qué es, aquí, «agnosia»?}

La simetría, desde luego, es buscada: «teología del agnóstico» / «agnosia del creyente». Cabría decir, para hacerla aún más literal: «agnosia del teólogo». Pero importaba subrayar que, tal como la entiendo, lo que llamo «agnosia» no viene sólo de la toma de consciencia de problemas culturales, sino de la misma raíz de la religiosidad vivida, de la misma fe en Dios.

El vocablo no es invención mía. Para preferirlo a otros me inclina, como he reconocido, su simetría con «agnosticismo», parecido y diferente a la vez. Pero no sólo. Como es sabido, «agnóstico» y «agnosticismo» no son más antiguos del siglo XIX: los encontró sir Thomas Huxley para expresar una postura de «no creyente en Dios» que no sugiriera todo lo que de asertivo y hasta polémico sugiere «ateísmo».

"Agnosia» (un término griego para decir «ignorancia») había sido aplicado, en cambio, mucho antes a lo de Dios. Lo hizo ya aquel escritor neoplatónico cristiano del siglo quinto cuyos escritos circularon con el seudónimo de Dionisio el Areopagita, que acudió al vocablo precisamente buscando expresar algo que sentía que era lo más importante que debía hacer en su esfuerzo teológico: evitar el desacato y la profanación que significaría una "teo-logía» (discurso sobre Dios) que no observara esa cautela. Intentaba sugerir con agnosia nada menos que el único modo de conocimiento que, a su parecer, puede tener sensatamente lugar en teología:

«... la agnosia es un conocimiento (gnôsis) del que está sobre todo conocimiento» (Carta 1, MG. 3, $1065 \mathrm{~A}$ )

No es -ya se está viendo- una ignorancia simple, que sería irrelevante. En un clima cultural en que se buscaba como salvador el conocimiento religioso (gnôsis) se hace una provocativa proclama de la agnosia como gnôsis.

Como puede apreciarse, eso es recurrir deliberadamente a la paradoja: la agnosia es gnôsis. Pero no se trata de un recurso alegre ni generalizador: lo que se busca mediante la antítesis no es establecer ninguna regla lógica general. Quiere, por el contrario, destacarse la singularidad del intento «teo-lógico» en cuanto tal. Porque ese intento busca conocer y expresar en lenguaje humano al «que está sobre todo conocimiento».

En este caso único -si es que hay motivos para no desistir simplemente del empeño-, lo único razonable es acudir a la paradoja -si es que se piensa que la paradoja puede al menos ser suficientemente indicativa-. 


\section{La «agnosia» del creyente}

El motivo para no desistir habrá, sin duda, que buscarlo en la vivencia de fe; de modo, posiblemente, complejo. Quizá es como querer asomarse al límite del mundo, en fuerza de la añoranza de un más allá que sea clave de su ser y su sentido.

Que la paradoja resulte suficientemente indicativa es algo que el Pseudo-Dionisio buscó elaborar un poco más en su escrito más valioso y cuidado, la Teología mística.

Las precisiones que aporta ese tratadito no son desdeñables. No hay unanimidad entre los estudiosos sobre el alcance a dar a algunas de sus expresiones. Pero pienso que la intuición básica queda clara en una formulación compendiosa que leemos muy al comienzo, donde describe un proceso que hoy, con término original platónico, llamaremos «dialéctica»:

«... siendo así que, más bien, es necesario afirmar de Él todas las posiciones (theseis) y afirmaciones, como Causa que es de todas; y, más necesario aún, negarlas, por cuanto está por encima de todas; sin pensar que las negaciones se oponen a las afirmaciones, sino, más bien, que la Causa está... sobre toda afirmación y negación» (De mystica Theologia, I,2, MG 3 $1000 \mathrm{~A}-\mathrm{B})$

Como vemos, el «sobre todo conocimiento» se precisa ahora en el sentido de un punto ideal (sin duda inalcanzable para el conocimiento y el lenguaje «normal») donde convergerían la afirmación de todo lo real y su negación.

Es compatible no tener simpatía por un recurso generalizado a la paradoja (sobre todo en quien no se siente místico ni poeta) y admitir que pueda ser el recurso más razonable para un ser humano que quiere dar expresión a una convicción de fe que le lleva a referir últimamente todo lo real al Misterio Absoluto.

En las grandes tradiciones religiosas de Asia algo así se ha intentado de modos varios, con acentos y orientaciones prácticas también varias. Hasta el silencio budista (que no es, naturalmente, un silencio cualquiera), pasando por las fórmulas a-dvaita («no-dualidad») del Vedanta.

Será éste, probablemente, el punto donde las tradiciones de religiosidad "profética» (Israel, cristianismo, islam) puedan alcanzar más coincidencia con esas otras tradiciones. Es cierto que en la religiosidad profética hay un rasgo diferente: es nuclear una actitud no sólo de adoración sino de invocación del Misterio, lo que equivale a atribuirle rasgos personales.

Hay aquí problemas no fáciles para la «teo-logía», es decir, para la expresión de una fe para la que el Misterio Absoluto es «Dios». Pero un prólogo para cualquier solución de tales problemas está quizá en compren- 
der que «Dios» en la fe monoteísta no es el singular de «dios, dioses...» de la simbólica politeísta; está más cerca de, aunque tampoco coincide con, el Brahman del Vedanta.

En todo caso, es muy relevante la postulación de agnosia que estoy comentando. Sobre todo, porque no es una ocurrencia feliz pero casual. Se le pueden encontrar paralelos en las tradiciones místicas de las tres religiones monoteístas.

$\mathrm{Y}$, por otra parte, el influjo del Pseudo-Areopagita ha sido grande en toda la tradición teológica cristiana. Le favoreció, sin duda, el seudónimo elegido. Pero eso no fue todo. $\mathrm{Y}$ entre los que se han mostrado influidos por él no están solamente teólogos tenidos por audaces como Nicolás de Cusa. Es marcadísima su impronta en Tomás de Aquino; determinando su decidida renuncia a tener por unívoca ninguna afirmación humana de Dios. (No se suele destacar el dato, pero el reciente Index thomisticus señala unas 1.300 referencias al corpus dionysianum, número sólo igualado por las de Aristóteles y Avicena).

Lo cual no ha impedido, hay que reconocer, que la teología cristiana habitual (incluida la tomista), haya sido en su práctica muy poco fiel al mensaje de la agnosia, multiplicando las afirmaciones teo-lógicas sin suficiente correctivo de negación.

Con lo cual, sin duda, tienen que ver su unilateral obsesión por el rigor en la ortodoxia doctrinal y la desmedida relevancia relativa que le ha concedido. El resultado ha sido con mucha frecuencia un talante dogmatista, sobre el que hay que preguntarse si es coherente con la fe en Dios, Misterio Absoluto «sobre todo conocimiento».

$\mathrm{Al}$ creyente reflexivo actual todo le lleva, por el contrario, a tomar en serio el «principio agnosia»; a evitar hacer con ligereza afirmaciones teológicas de pretensión científica y a resituar los énfasis en su comprensión de la fe.

\section{«Agnosia»y $\boldsymbol{y}$ agnosticismo»}

El creyente cristiano reflexivo sigue hoy hablando de Dios, pero lo hace con más respeto, con «temor y temblor». Redescubre con gozo lo que su tradición mantenía sobre la indispensable agnosia; y, al hacerlo, es consciente de no ejercer con ello estrategia ninguna, sino, más bien, ser simplemente coherente con lo que quiere decir al decir «Dios».

Sigue en pie su diferencia con el «agnóstico»; y una diferencia no simplemente gradual. Pero, bien concebida, tal diferencia no afecta propiamente a lo que «saben». Ambos saben en principio lo mismo sobre el mun- 
do y el hombre; y ambos pueden asumir entre sus rasgos una cierta profesión de «no saber» en cuanto al posible Misterio, al que no llega el saber científico.

Lo que los diferencia es una convicción, que es parte de la compleja actitud vital y en la que, sin duda, pesa toda la biografía. El creyente refiere todo, en su actitud de fe, a un Misterio Absoluto al que, precisamente porque lo es, profesa no poder alcanzar con su saber y sí sólo atisbar como un punto límite. El agnóstico tiene otra convicción más sobria: estando así las cosas, tiene por más razonable atenerse a lo que se puede saber.

Pero, desde este ángulo de visión, se hace ya sin duda muy comprensible que un agnóstico se entienda bien con los creyentes reflexivos que han llegado a descubrir el esencial anidamiento de la agnosia en cualquier intento suyo de expresar en palabras humanas lo que viven en su fe en Dios. Así como que esos creyentes puedan a veces sentirse más cercanos a ciertos agnósticos que a los «gnósticos» muy seguros en sus dogmas (religiosos o cientistas).

De muchos agnósticos habrán sin duda aprendido los creyentes dialogantes una especial honradez intelectual que prohíbe capitular ante el autoengaño cómodo. Conscientes, por otra parte, de que no tendrían que abdicar de la convicción creyente por el hecho de que ésta encuentre una profunda complicidad con el fondo del deseo humano de bien.

A los agnósticos agradecerán también esos creyentes no poco en el importante descubrimiento de la agnosia. Algo que estiman como una maduración, no sólo humana sino también de su fe. Porque una fe sin «principio agnosia», una fe que se sintiera feliz pensando cautivar al Misterio Absoluto que invoca como «Dios» en la pobre red de sus dogmas es no sólo humanamente inmadura sino profundamente incoherente con su propio fondo vivido.

Y aquí puede incluso producirse una situación no poco paradójica. Puede ocurrir que, en el diálogo mutuo, el agnóstico que se interesa por la teología ponga en apuro al creyente al pedirle aclaraciones conceptuales referidas a las formulaciones tradicionales de la fe; con el resultado de que haya de ser el creyente quien recuerde al agnóstico el "principio agnosia».

\section{El enigma de la religión}

Veo oportuno terminar retornando desde lo dicho el título general del monográfico. Cuando hablamos hoy de la religión como enigma, la miramos ante todo «desde fuera», con los ojos del historiador y del estudioso 
de ciencias humanas. Hemos descubierto que esa consideración es importante para nuestra reflexión total sobre el ser humano y su cultura. Visto así, resulta muy adecuado el título elegido.

La religión es enigma porque, en la descripción objetiva del ser humano, hace presente un excedente de significado. ¿Por qué tienen los seres humanos, además de tantas actuaciones y actitudes más explicables, nacidas de sus búsquedas de sobrevivencia y comunicación, esas otras que llamamos religiosas, tan extrañas, tan diversas también entre sí?

La enigmática religión hace enigmático al ser humano. $O$, quizá, siendo los humanos enigmáticos por más de un título, la dimensión religiosa es la que más los revela como tales.

Ahora bien, es lógico preguntarse también: ¿es también enigma la religión para aquellos de los humanos que la viven «desde dentro»? Cabría pensar que no. En las culturas tradicionales, los símbolos, ritos y creencias religiosas -el cosmos sagrado en la denominación de Thomas Luckmann-, forman parte de lo más obvio del universo de significados y prácticas. Para que puedan cumplir bien la función que les reconoce la sociología de «dar sentido a la vida personal y social», parece necesaria esa índole de supuesto indiscutido.

Pero ello no quita que la experiencia religiosa tenga para quien la vive, incluso en esa situación y sin dependencia de ninguna especial reflexión, una peculiar índole de enigma, que esta vez cabría llamar enigmaticidad constitutiva.

El continuo moverse en el universo de los símbolos marca al ser humano, le deja entrever la radical ambigüedad del vivir humano; le hace consciente de lo ilimitado de su deseo y del contraste con lo que puede ofrecerle la realidad, del valor de mantener esperanza incluso entonces y de la precariedad del mantenerla. Quizá es esa enigmaticidad la cara más cercana de lo que llamamos «lo sagrado»; y es a sus experiencias multiformes a lo que podemos llamar «hierofanías».

Para los humanos de nuestras culturas modernas (¿y posmodernas?) la religión ha dejado de constituir un supuesto indiscutido; y se nos ha hecho con ello más obvio mirarla objetivamente como enigma y hablar en ese sentido de «el enigma de la religión». Pero ello no agota la enigmaticidad: la misma religión se refiere al enigma de la existencia y revela al ser humano su implicación en él.

El que hoy hayamos aprendido el valor de mirar a la religión «desde fuera», ¿es simplemente desfavorable para las experiencias religiosas y para la percepción de esa otra, constitutiva, enigmaticidad?

Algo hay que inclina sin dudas a la respuesta afirmativa. Pero quizá no tendría que ser esa la última palabra. Más que hacerse imposibles, las 
«hierofanías» pueden haber cambiado de medio expresivo y de lugar; quizá hacia lo hondo de la relación interhumana. Allí hará de nuevo acto de presencia lo enigmático.

Y quizá entre las notas de enigmaticidad de experiencias de fe monoteísta viables hoy haya de reconocerse cada vez más lugar muy relevante a la agnosia. 